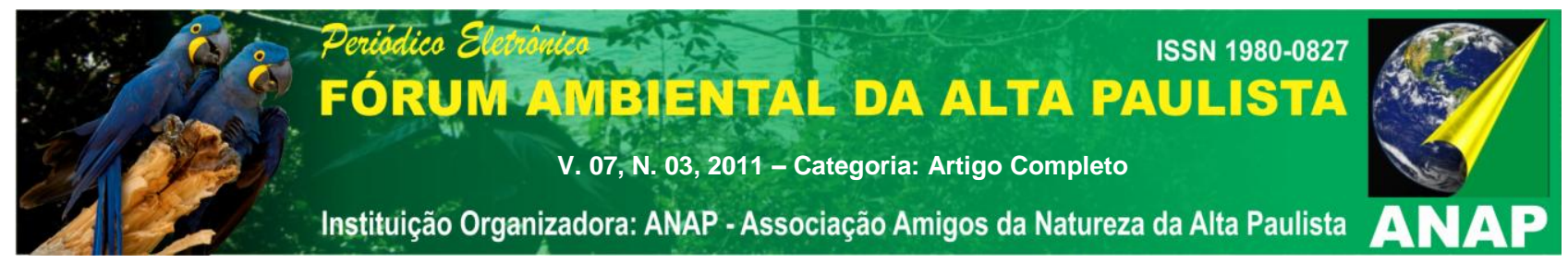

\title{
O DESFLORESTAMENTO DA MATA ATLÂNTICA CAUSADO PELAS ATIVIDADES ECONÔMICAS, EM ESPECIAL O CULTIVO DO CAFÉ
}

\author{
Thiago Corrêa Muniz ${ }^{1}$
}

\begin{abstract}
Resumo: Depois de decorridos 511 anos do descobrimento do Brasil pelo colonizador português, ficamos preocupados com o avançado estado de degradação ambiental em que se encontra a Mata Atlântica. Este é o resultado do modelo de ocupação do espaço geográfico brasileiro, voltado para atender as necessidades da metrópole portuguesa. Após anos de exploração dos solos e das riquezas florestais de nosso país, o que temos do bioma Mata Atlântica, são apenas resquícios dessa outrora imponente floresta tropical. Este artigo trata, de maneira abreviada, da história da ocupação das terras que um dia foram ocupadas pela Mata Atlântica, hoje bastante fragmentada sendo um dos hotspots mais ameaçados do mundo, com apenas $8 \%$ de sua cobertura original.
\end{abstract}

Palavras-chave: desflorestamento; Mata Atlântica; café.

\section{Introdução}

O presente artigo tem como objetivo principal abordar, embora de maneira sucinta, um tema cada vez mais atual, a preservação, ou melhor, a destruição, como preferir o leitor, dos remanescentes florestais em nosso país.

O Brasil é um país de proporções continentais, tem uma área total de 8.547.403 $\mathrm{Km}^{2}$, o que nos coloca na quinta posição no ranking dos maiores países do mundo em termos de extensão territorial. Devido, entre outros fatores, à nossa

\footnotetext{
${ }^{1}$ Licenciado em Geografia pela Universidade Federal de Juiz de Fora, professor de escolas das redes pública e particular do município de São João Nepomuceno, MG.
} 


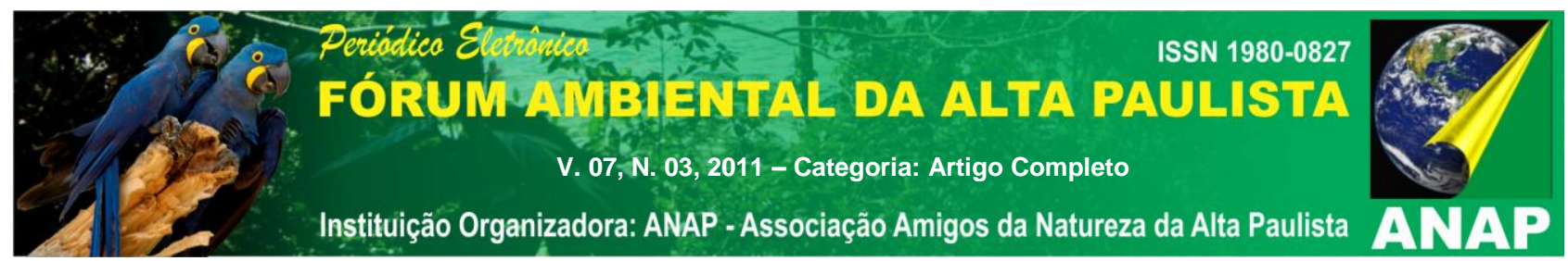

localização na faixa tropical do planeta, contamos, de Norte a Sul e de Leste a Oeste, com uma grande variedade de climas e solos; são igualmente variadas as estruturas e formas de nossos relevos. Em meio à tamanha grandeza e espalhando-se por todo o país, as espécies da fauna e da flora, dão-nos o status de país Megadiverso.

Em território brasileiro são encontrados uma enorme gama de minerais o que torna valioso o nosso subsolo. As bacias hidrográficas brasileiras são responsáveis por uma riqueza hídrica incomensurável, principalmente em tempos de escassez de água potável. São dignas de nota a bacia hidrográfica do rio Amazonas e o Aqǘfero Guarani, as maiores reservas de água doce, respectivamente, de superfície e subterrânea do planeta.

Tratando mais especificamente das formações vegetais do nosso país, aprendemos com os autores José Bueno Conti (2001) e Sueli Angelo Furlan que:

As florestas tropicais e subtropicais que ocorrem no Brasil desenvolvemse em mosaicos com diferentes associações vegetais. Algumas características climáticas ou mesmo fenológicas são usadas para identificar essas associações e tipos: pluviais, deciduais, semi-secas, montanas etc. Dentro de seu domínio próprio, as florestas brasileiras apresentam enclaves de formações não-florestais, como as campinaranas na Amazônia ou os campos de altitude na Mata Atlântica.

Além das grandes extensões de florestas o Brasil apresenta dois grandes domínios de formações vegetais abertas e semi-abertas: as caatingas e os cerrados. No mapa do Brasil esses dois domínios formam uma diagonal de climas mais secos que percorre o país do Nordeste ao Pantanal mato-grossense, passando pelo Brasil Central. (CONTI, FURLAN, 2001, p. 155).

Buscando delimitar o objeto de análise do presente artigo, pensei escrever mais detidamente sobre o bioma Mata Atlântica. Certo que não seria possível esgotar o tema do desflorestamento da citada formação vegetal em um simples artigo, procedi a um breve levantamento das atividades econômicas que, ao longo da história recente de nosso país, contribuíram para o estado deplorável de conservação em que se encontra hoje a Mata Atlântica. Como veremos a seguir, 


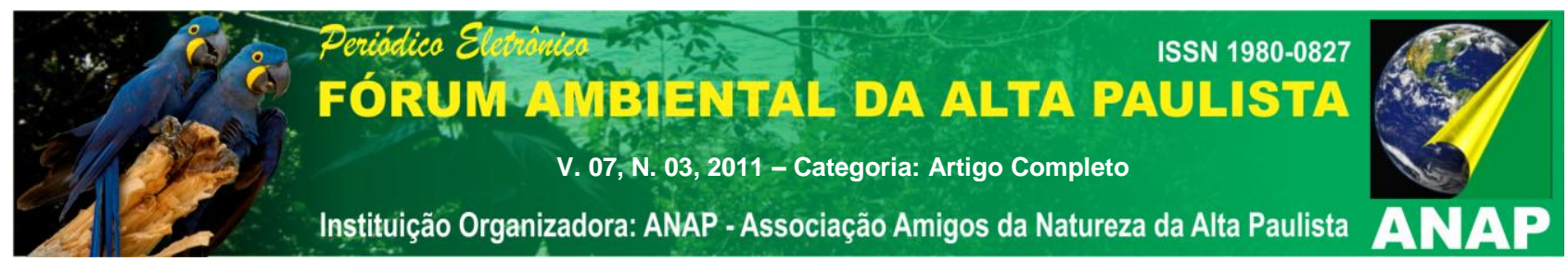

foram várias as atividades que, desde a chegada do colonizador em terras brasileiras, até os dias atuais, contribuíram tanto para a riqueza da metrópole portuguesa - no tempo em que ainda éramos colônia daquele país - quanto para a depauperização de nosso meio ambiente.

O café mereceu neste artigo atenção especial. A cultura cafeeira, mais do que outras atividades econômicas tratadas nestas linhas foi a responsável pela opulência de seus produtores, pela instalação de infra-estrutura que viabilizasse a exportação do café para o mundo, fez surgir cidades tão rapidamente quanto fêlas desaparecer, tornou o Brasil conhecido em todo o mundo, viabilizando inclusive a industrialização do estado de São Paulo. Mas este mesmo café cobrou um preço altíssimo em destruição da Mata Attântica.

\section{A Mata Atlântica}

Segundo os ensinamentos de Valverde em seu "Estudo Regional da Zona da Mata, de Minas Gerais", publicado originalmente na edição de Janeiro-Março de 1958 da Revista Brasileira de Geografia, a Zona da Mata, que recebe esta denominação graças à sua cobertura vegetal original de Mata Atlântica "formava um todo contínuo com a floresta do médio Paraíba, ao sul, e a do vale do rio Doce, ao norte. A oeste, limitavam-na os campos naturais do centro e do Sul de Minas". (VALVERDE, 1958, p.7). Originalmente a Mata Atlântica ocupava cerca de 1 milhão de quilômetros quadrados ao longo do litoral Leste da América do Sul, como podemos observar no mapa em anexo.

A Mata Atlântica

[...] era o habitat de um grande número de espécies endêmicas, figurando como uma importante área de biodiversidade juntamente com a Floresta Amazônica, com a qual esteve em contato parcial por longos períodos geológicos. Um conjunto de fatores tais como relevo, correntes marítimas e regimes de vento podem explicar a ocorrência desta formação vegetal que 


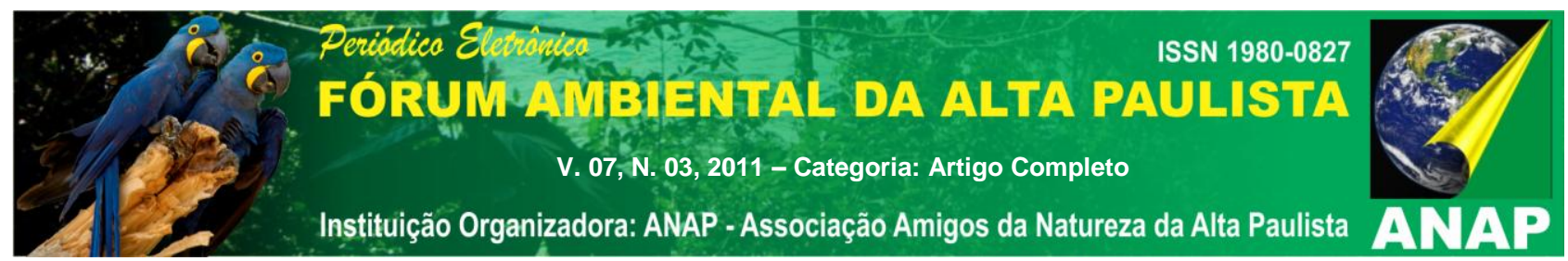

se ergue em terrenos com predominância de Latossolos Vermelho-Amarelos, solos que se apresentam sempre muito profundos e pobres em nutrientes para as plantas. A resistência à erosão, embora elevada, possui limitações claras em função de sua ocorrência em relevos ondulados, em clima predominantemente chuvoso. (GIOVANINI, SILVA MATOS, p. 3).

Atualmente podemos observar alguns poucos remanescentes de mata secundária, geralmente localizados nos topos dos morros da região, denotando um longo processo de devastação provocado por décadas de intenso aproveitamento econômico das terras outrora ocupadas por esse grande bioma brasileiro, "um dos hotspots mais ameaçados do mundo, reduzido a $8 \%$ de sua área original." (COSTA, 2006, p. 9).

$\mathrm{Na}$ área de abrangência da Mata Atlântica, o colonizador sempre encontrou campo propício para o crescimento econômico, primeiramente da metrópole portuguesa e logo em seguida, da própria colônia. Quando voltamos os olhos para os primórdios da nossa história, lembramos que a primeira atividade econômica desenvolvida em "terras tupiniquins" foi a extração do pau-brasil - árvore típica do bioma Mata Atlântica - que aguçou a cobiça dos exploradores portugueses como podemos observar na correspondência de Américo Vespúcio a Piero Soderini, contando de sua primeira viagem ao Brasil: "Nessa costa não vimos coisa de proveito, exceto uma infinidade de árvores de pau-brasil (...)". (BUENO, 1998, p. $65)$.

Ainda segundo o jornalista Eduardo Bueno (1998) em seu livro "Náufragos, Traficantes e Degredados: As Primeiras Expedições ao Brasil":

Desde o século $\mathrm{XI}$, a Europa estava familiarizada com o pau-brasil, embora de uma espécie diferente daquela encontrada no Brasil. Nativa de Sumatra, a árvore - chamada, em malaio, de "sapang" (do sânscrito "patanga" ou "vermelho") - era exportada para a Índia desde tempos imemoriais. Dali, os mercadores árabes a levavam para o Egito, pela via do mar Vermelho. Usado desde a aurora da era cristã para tingir as sedas e os linhos trajados pelos nobres do Oriente, o pó de sapang concedia a esses tecidos "um suntuoso tom carmesim ou purpúreo". (BUENO, 1998, p. 68). 


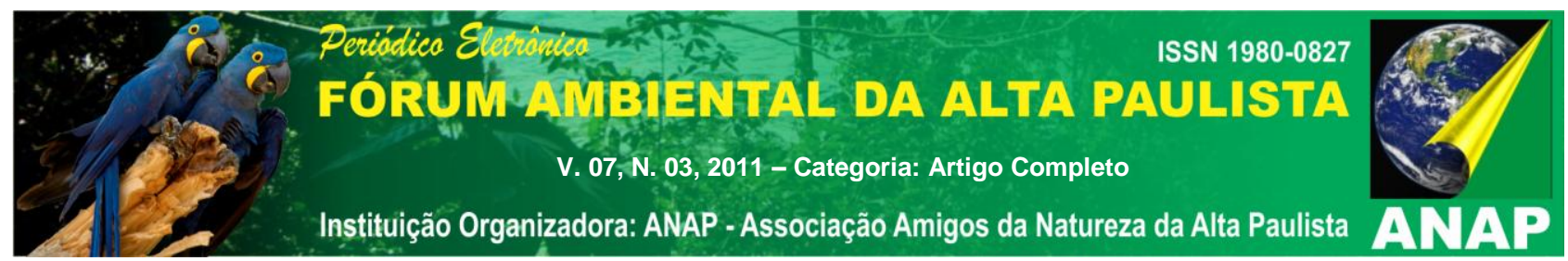

A exploração da Caesalpinea echinata, nome científico do pau-brasil, das matas costeiras do Brasil foi tão intensa, que forçou a Coroa portuguesa a criar no ano de 1605, a figura dos guardas florestais, com o receio de que, "com o corte indiscriminado e a estocagem, as madeiras "virão a acabar e perder de todo". (DEAN, 2010, p. 64).

Avançando um pouco mais na história de devastação da Mata Atlântica, chegamos aos séculos XVI e XVII, quando uma nova atividade econômica floresce, principalmente na região da Zona da Mata nordestina, a empresa açucareira. A cana de açúcar foi originalmente introduzida na Capitania de São Vicente, no litoral de São Paulo, porém encontrou seu eldorado no litoral nordestino na faixa que se estende do Rio Grande do Norte até o sul da Bahia. Nesta região encontramos o solo de massapé, elemento fundamental para a cultura açucareira por ser um solo de média e alta fertilidade, que combinado ao clima litorâneo úmido da região com médias anuais de temperatura girando em torno dos $24^{\circ} \mathrm{C}$ e $26^{\circ} \mathrm{C}$ com índice pluviométrico anual entre 1.000 e $2.000 \mathrm{~mm}$, contribuíram para o bom desempenho da Zona da Mata nordestina no tocante à produção agrícola do açúcar.

A agroindústria do açúcar desenvolveu-se tendo como premissas o latifúndio, a monocultura e o trabalho escravo, e foi uma atividade determinante para a produção do espaço geográfico nordestino, tomando o lugar da Mata Atlântica. Ainda hoje a Zona da Mata nordestina permanece como área de produção açucareira, apesar das características da produção terem mudado muito, como por exemplo, a substituição da mão de obra escrava pela assalariada, representada nos dias atuais pela figura dos bóias frias e a substituição dos antigos engenhos por usinas de açúcar e álcool. A cana de açúcar hoje divide o espaço agrícola da região com outras importantes culturas como o tabaco, o cacau e as frutas tropicais. Toda essa atividade agrícola, que, como notamos, 


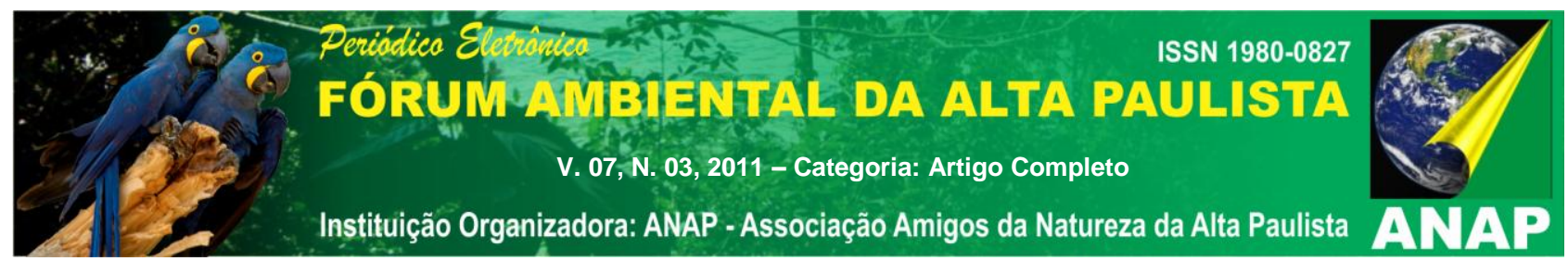

remonta aos primeiros anos do Brasil colônia, apesar de mola propulsora do desenvolvimento nordestino, deixou como herança um pesado custo ambiental.

Estudos recentes realizados pela fundação SOS Mata Atlântica em conjunto com o Instituto Nacional de Pesquisas Espaciais - o INPE - compilados na publicação intitulada Atlas dos Remanescentes Florestais de Mata Atlântica, apontam o estado da Bahia como o segundo maior no ranking do desmatamento no período estudado, (2008 a 2010), com um total de 7.725ha do bioma Mata Atlântica destruído, atrás apenas do estado de Minas Gerais, o grande vilão dos remanescentes de Mata Atlântica, com um total de 12.467ha de mata destruída.

O final do século XVII traz para o Brasil uma nova realidade. A agricultura canavieira do Nordeste entra em declínio devido à concorrência no mercado mundial da produção do açúcar das colônias antilhanas da Holanda, Inglaterra e da França. Em substituição ao açúcar nordestino surgem o ouro e os diamantes.

No Brasil do século XVIII, a descoberta de ouro e diamantes, marcam uma nova etapa da exploração da Mata Atlântica. Nesse período, essas riquezas minerais serão as responsáveis pelo incremento populacional no país e pela elevação do seu "status"; o Brasil, aos olhos da Coroa portuguesa, passa de governadoria-real a vice-reino. E não é para menos,

De 1700 a 1800, 1 milhão de quilos de ouro foram oficialmente registrados e talvez outro milhão tenha escapado ao fisco real. Cerca de 2,4 milhões de quilates de diamantes foram extraídos, segundo registros oficiais e uma quantia adicional desconhecida e incalculável foi contrabandeada. (DEAN, 2010, p. 108).

A principal destruição trazida pelo ouro foi representada pelo incremento populacional, a maior intensidade desta atividade econômica, pois nesta época histórica, o ouro era o responsável pelo poderio das grandes potências e a forma 


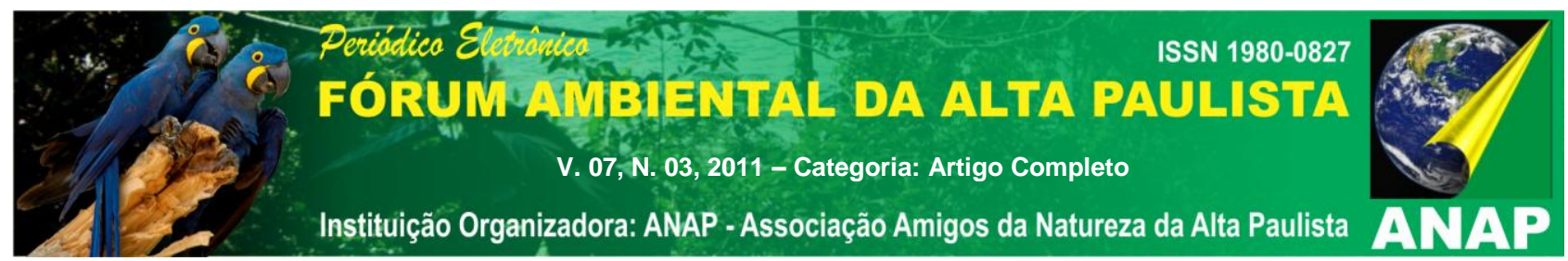

como era explorado, com o desvio do curso de alguns riachos e a dragagem de rios maiores.

Como mais uma vez nos ensina Warren Dean, "a degradação provocada pela mineração foi mais intensa nas planícies aluviais cheias de cascalho e nos fundos dos rios." Ainda segundo este autor, "O ouro também era encontrado em sopés de montanhas, em certos tipos de argila a um metro ou dois de profundidade e em formações rochosas friáveis. Nesse tipo de terreno, a floresta era queimada - grandes parcelas dela, (...)." (DEAN, 2010, p. 113).

Porém o ouro brasileiro, que tanta esperança havia dado à metrópole portuguesa no início do século XVIII, já em 1780 dava sinais de esgotamento, pois segundo a autora Melhem Adas, "cerca de 85\% do ouro extraído nas Minas Gerais era de aluvião, de rápido esgotamento, (...)." (ADAS, 1998, P. 69). Junte-se a isso a deficiência de equipamentos da época colonial e a incompetência para a descoberta de novos filões e teremos a derrocada precoce da mineração aurífera no Brasil. Em substituição ao ouro e aos diamantes como principais riquezas brasileiras, surge o café, o ouro verde, responsável, também ele, por uma devastação ímpar das terras recobertas de Mata Atlântica. Planta que deu origem a grandes fortunas, fez surgir cidades, responsável pela implantação de ferrovias, financiador da industrialização brasileira, foi também um dos vilões do bioma analisado neste artigo.

\section{O café}

O café ou Coffea arábica, como nos ensina o escritor Warren Dean (2010) em sua obra intitulada "A Ferro e Fogo", é uma pequena árvore da família das rubeáceas, nativa do Sudoeste do planalto da Etiópia. A pequena fruta avermelhada que nasce de uma flor branca do pé de café, foi descoberta por volta 


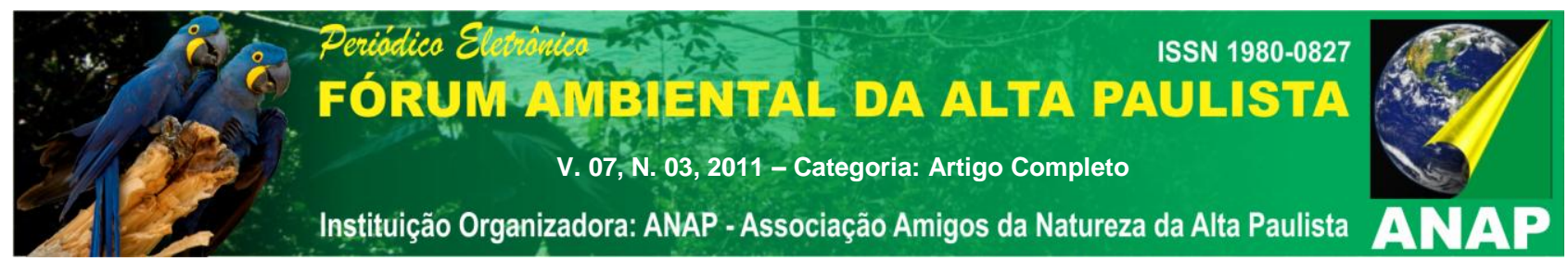

do ano de 525 no interior daquele país. Encontraremos, em manuscritos do lêmen, país do Sudoeste asiático, a primeira referência à utilização comestível desta fruta.

Segundo uma lenda lemenita, conhecida como a Lenda de Kaldi, um pastor de cabras etíope observou que seu rebanho, ao consumir as folhas e os frutos de determinado arbusto, sofria um efeito excitante. Os animais, quando mastigavam a planta, subiam as montanhas com agilidade e resistência. Kaldi então experimenta os frutos excitando-se também e a partir desta experiência, dissemina o consumo da frutinha pela região. (MARTINS, 2010, p. 21)

Na Etiópia, país de origem do café, sua polpa doce, macerada ou por vezes misturada em banha, era refeição bastante apreciada. Da fruta também se produzia um suco que, ao fermentar, era servido como bebida alcoólica. Suas folhas eram mastigadas ou utilizadas na fabricação de chás e seus frutos foram também utilizados com fins medicinas, depois de preparados em água fervente. Com a torrefação destes frutos já no século XIV, teremos a bebida tão apreciada que conhecemos hoje.

Da Etiópia o café foi levado à Península Arábica, sendo os árabes os primeiros a dominar as técnicas de plantio e preparação do produto. Da Península Arábica, as primeiras sementes do café foram enviadas ao lêmen, onde passaram a ser cultivadas comercialmente, em duas variedades, a "típica" e a variedade "Bourbon". Estas variedades foram a origem de todo o café que se espalhou por todo o Sul e Sudeste da Ásia e pelo Novo Mundo, tendo chegado ao Brasil por volta de 1600, possivelmente vindo da Índia. Ainda segundo os dizeres de Dean (2010):

Uma possível segunda introdução ocorreu em 1727: os franceses haviam recebido café dos holandeses e o transferiram para a Guiana Francesa. Um oficial da armada brasileira, para lá enviado a fim de verificar a situação da fronteira, carregara sub-repticiamente para Belém do Pará um punhado de sementes geradas por essas árvores. Ali e no vizinho Maranhão, logo se tornou um produto comercial modesto. (DEAN, 2010, p. 194) 


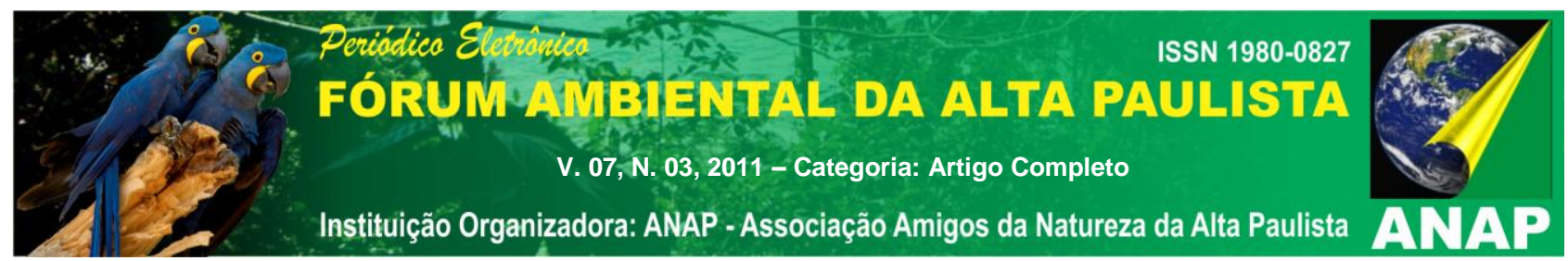

Do Maranhão estas sementes podem ter sido levadas ao Rio de Janeiro por volta de 1752 ou 1762, onde foram introduzidas no horto do mosteiro dos capuchinhos.

A variedade Bourbon teria chegado ao Brasil em 1782, tornando-se por volta de 1790 uma atividade comercial voltada para o mercado interno. No Rio de Janeiro, o café encontra ambiente adequado para o seu cultivo, constituindo-se a base da economia brasileira, destacando-se na evolução histórica social do nosso país. A produção cafeeira no Brasil tem conseqüências sociais, culturais e ambientais que marcaram profundamente a nossa história e as nossas paisagens geográficas. (DEAN, 2010, p. 194)

Trata-se de um produto que, segundo Roberto Simonsen, citado por J. R. de Araújo Filho em seu artigo O café, riqueza paulista: “(...) da independência até o ano de 1938, para um total da exportação brasileira de 3 bilhões e 400 milhões de libras esterlinas, o café, sozinho, concorre com 2 bilhões!". Se compararmos a produção do café com a produção açucareira, outro grande produto oriundo da economia primária do Brasil colônia, que rendeu 300 milhões de libras esterlinas (FILHO, Boletim paulista de Geografia, p.51), podemos notar facilmente a grandeza econômica do café. Mas, nos perguntamos, qual o preço pago pela Mata Atlântica por tantos anos de exploração econômica? Qual teria sido o legado ambiental do café e das demais atividades abordadas neste pequeno artigo?

Segundo o professor Paulo Henrique Martinez, da Universidade Estadual Paulista Júlio de Mesquita Filho (UNESP), em recente artigo escrito para a revista História, da Biblioteca Nacional,

O café moldou a paisagem rural e urbana no Centro-Sul do Brasil a partir do século XIX. Enormes áreas de florestas e cerrados foram cortadas e queimadas para dar lugar aos cafezais, a cidades e ferrovias. (...). Enquanto o solo desnudo aguarda novo plantio, nada de árvores, rios, florestas, bichos ou pessoas. 


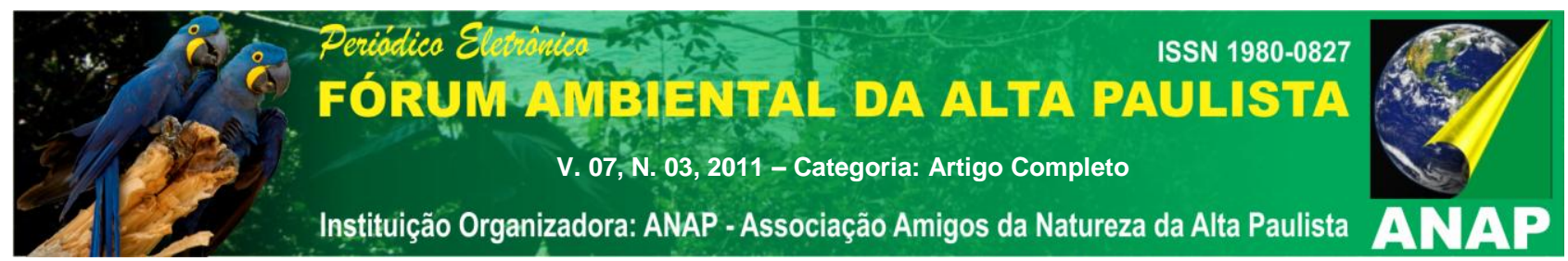

A Mata Atlântica, que dominava os territórios de Rio de Janeiro, São Paulo, Minas Gerais, Espírito Santo e Paraná, ficou reduzida aos terrenos íngremes, fundos de vale e áreas pouco atraentes para a agropecuária.

Não restam dúvidas sobre a importância do café para o crescimento do Brasil. Este produto agrícola, de enorme peso econômico, foi o responsável pelo surgimento de uma oligarquia cafeeira em nosso país. Os Barões do café, título dado aos grandes cafeicultores paulistas, dividiram as rédeas da política nacional com os produtores de leite de Minas Gerais durante a República Velha, (18981930) - culminando com a política dos governadores já no governo de Campos Sales. Na conta do café também podemos colocar a vinda de imigrantes ao país, em substituição à mão de obra escrava, largamente utilizada nas plantações. Os enormes lucros obtidos pela cultura do café acabaram por tornar o desenvolvimento regional brasileiro um tanto quanto desigual, principalmente quando se colocam frente a frente as regiões Sudeste e Nordeste do país, esta economicamente atrasada em relação àquela.

O ciclo do café, que se inicia em 1800, chega ao fim no ano de 1930 , impulsionado pela crise mundial de 1929, o que provocou redução da demanda mundial e a queda nos preços do produto, forçando o governo brasileiro, Getúlio Vargas, a comprar os excedentes de produção, numa tentativa de socorrer os produtores em meio a esta grande crise econômica internacional.

\section{Conclusão}

O Brasil é um país de vocação agrícola, fato este que vem sendo comprovado desde o período colonial até hoje. Passando pela exploração de madeira no litoral, pelo plantio da cana-de-açúcar no litoral nordestino, pelo café 


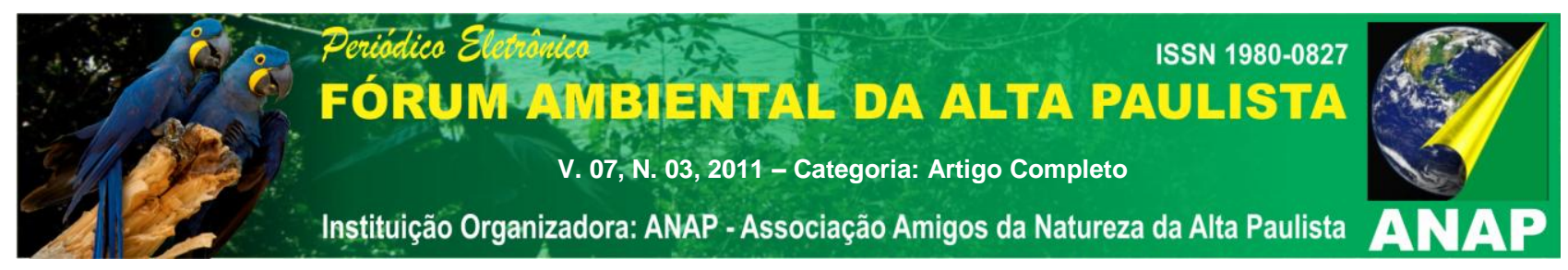

do vale do rio Paraíba do Sul e chegando aos cultivos de soja e frutas tropicais, presentes em quase todo o território, nosso país, considerado por muitos como o "celeiro do mundo", tem na atividade agropecuária uma importante fonte de emprego e renda.

Segundo informações do Ministério da Agricultura, Pecuária e Abastecimento, o Brasil "é o primeiro produtor e exportador de café, açúcar, etanol e suco de laranja" (...). O país sustenta ainda o título de um dos líderes no ranking das exportações de farelo, grão e óleo de soja, ainda segundo informações encontradas no site do Ministério da Agricultura. Toda esta pujança faz com que o Brasil figure entre os grandes da economia mundial e contribui para o crescimento da nação, indubitavelmente. Porém, cabe ainda uma pergunta, a meu ver fundamental: o crescimento econômico brasileiro se dá em bases sustentáveis?

Este pequeno artigo não pretende, de maneira alguma, apontar o café como o vilão da degradação das áreas de Mata Atlântica no país. Como pudemos acompanhar, ainda que brevemente nestas poucas linhas, nosso território, tão vasto e diverso em climas, biomas e recursos minerais, foi campo propício à exploração de vários produtos que fizeram a riqueza de muitos, mas que contribuíram para levar as nossas formações vegetais, em especial a Mata Atlântica, quase ao esgotamento.

O café foi e é um dos grandes produtos do agronegócio brasileiro. Este fruto não tem nenhuma especificidade que possa ser apontada como responsável pela degradação das áreas em que é plantado, mas aqui no Brasil, em especial na região Sudeste, encontrou solos e climas propícios para o seu desenvolvimento. Sua imensa aceitação no mercado internacional, conseqüência da qualidade do produto, acabou por gerar grandes riquezas e poder aos seus produtores. Por conseguinte, o café acabou por ocupar imensas áreas que antes eram cobertas pela Mata Atlântica, sem que se tomasse nenhum cuidado especial com o bioma que estava sendo suprimido. Desta forma, diversas espécies vegetais e animais 


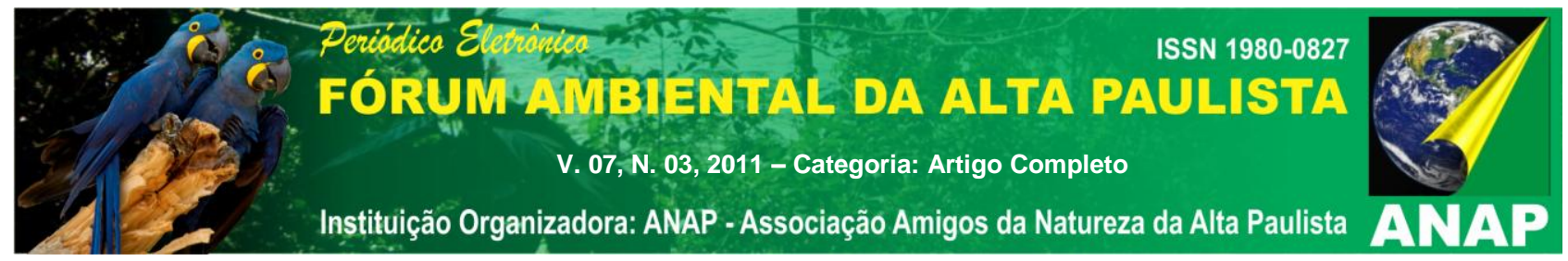

forma extintas. Atualmente, o café é cultivado em 14 estados brasileiros, com área plantada de 2,3 milhões de hectares (Ministério da Agricultura, Pecuária e Abastecimento, acesso em: 8/7/2011), continua, portanto, a gerar divisas para 0 Estado e para seus produtores, todavia continuamos a observar como já citado no artigo, a diminuição das áreas de Mata Atlântica do Brasil.

Anexo: A Mata Atlântica brasileira em 1500.

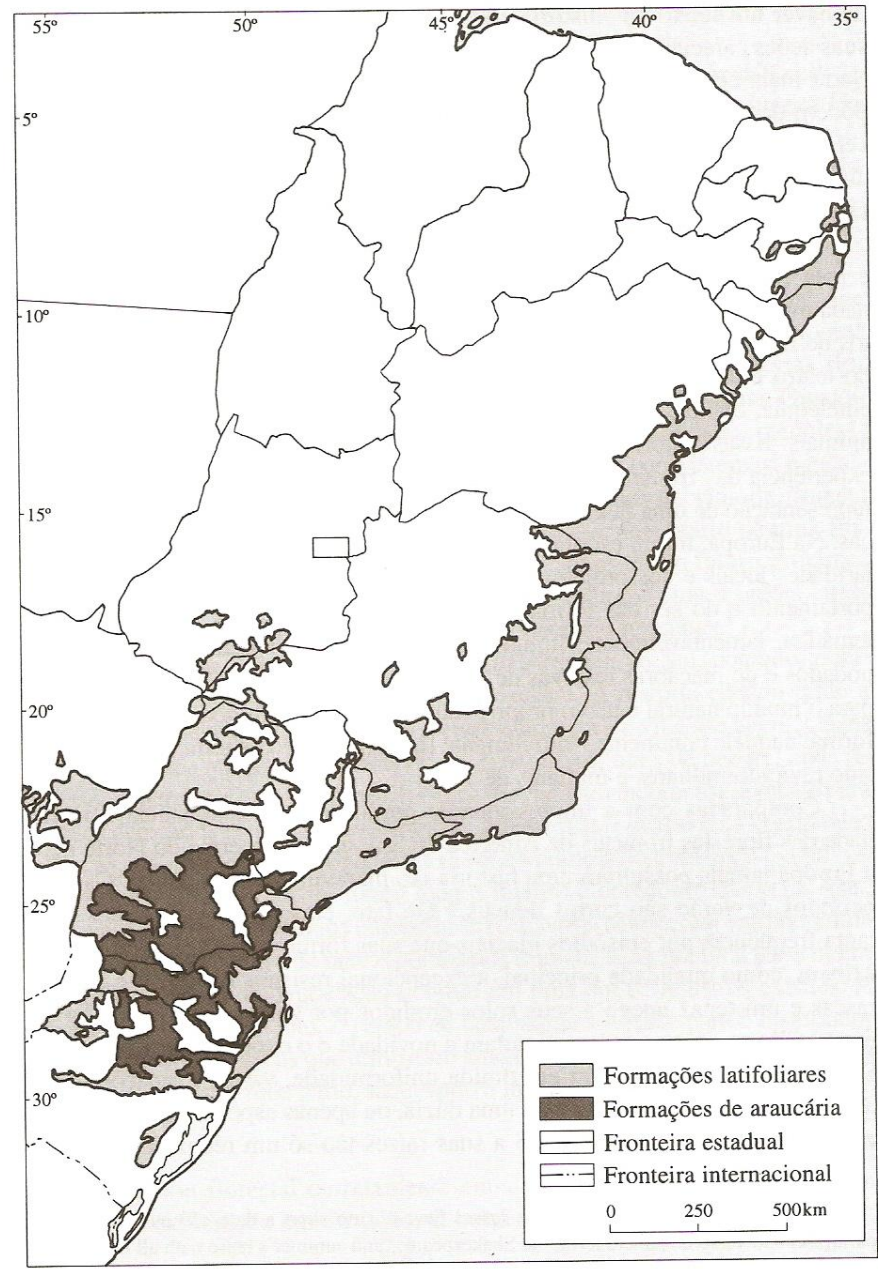

Mapa 1. A Mata Atlântica brasileira em 1500

Fonte: DEAN, Warren. A Ferro e Fogo, a história e a devastação da Mata Atlântica Brasileira. São Paulo: Companhia das Letras, 1996. 


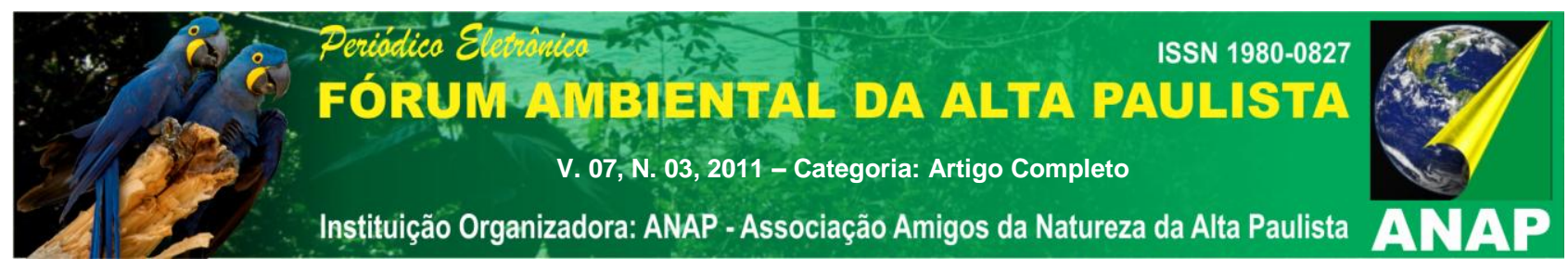

\section{REFERÊNCIAS BIBLIOGRÁFICAS}

BUENO, Eduardo. Náufragos, Traficantes e Degredados: as primeiras expedições ao Brasil, 1500-1531. Rio de Janeiro: Objetiva, 1998.

COSTA, Cláudia Maria Rocha. RPPN Mata Atlântica: potencial para implantação de políticas de incentivo às RPPNs. Belo Horizonte: Conservação Internacional, Fundação SOS Mata Atlântica, The Nature Conservancy, 2006.

DEAN, Warren. A Ferro e Fogo, a história e a devastação da Mata Atlântica Brasileira. Tradução Cid Knipel Moreira; revisão técnica José Augusto Drummond. São Paulo: Companhia das Letras, 1996.

GIOVANINI, Rafael Rangel e MATOS, Ralfo Edmundo da Silva. Geohistória econômica da Zona da Mata Mineira.

ROSS, Jurandyr L. Sanches (Org.). Geografia do Brasil. 4 ed. São Paulo: Editora da Universidade de São Paulo, 2001.

VALVERDE, Orlando. Estudo Regional da Zona da Mata, de Minas Gerais. Revista Brasileira de Geografia, Rio de Janeiro, v.20, n.1, p. 3-82, jan-mar 1958.

\section{PERIÓDICOS CONSULTADOS}

Revista de História da biblioteca Nacional. Edição № 57, ano 5. Junho de 2010.

<www.agricultura.gov.br>. Acesso em: 8 de Julho de 2011.

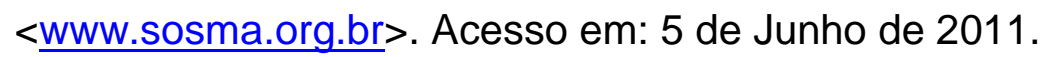




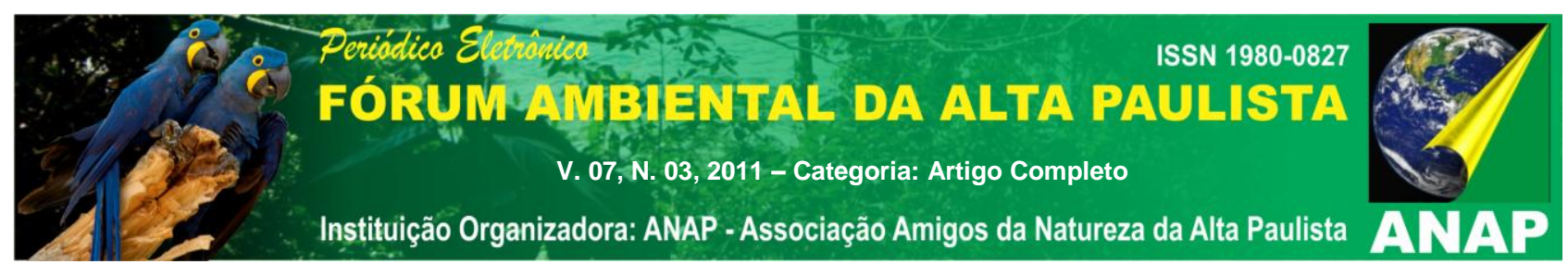

